\title{
Arbor
}

\section{Lo tradicional, lo ideal y lo universal del Palacio Real de Madrid}

\author{
Virginia Tovar Martín
}

Arbor CLXIX, 665 (Mayo 2001), 1-13 pp.

El Nuevo Palacio Real de Madrid se presenta a los ojos de quien lo mira, como un ser «satisfecho» ante la realidad de su mundo y del esplendor de su época. Entregado a la creatividad artística plena del siglo XVIII, esta hermosa obra escapa, en gran parte, hacia mundos inéditos y desconocidos en España, gracias a un encuentro afortunado, puramente creador, que hizo posible su arquitecto, Juan Bautista Saquetti, al combinar con su imaginación, el paisaje sereno y armónico del barroco europeo clásico y tardío, y el paisaje melancólico del alma romántica evocadora de nuestra tradición hispánica. El Palacio Real alcanza, como obra arquitectónica, una cierta unidad esencial y una totalidad coherente, pero revela, también, en el horizonte de su mundo material, o del mundo de su espíritu, en el impulso de su gran vitalidad, diversas vertientes desplegadas, pero a la vez imbricadas en sus complementarios elementos, perfectamente expresadas a través de las líneas maestras, que definen el verdadero espíritu pragmático y teorizante de una época, culturalmente espléndida.

Muchos de sus rasgos coinciden con las líneas generales de la modernidad, muchos de sus componentes siguen, de manera contundente, los pronunciados surcos trazados por el barroco de esplendor europeo. Incluidas sus disonancias, el Palacio Real, sin embargo, no pudo satisfacerse tan solo con las esencias inteligibles de este estilo y sus variantes, a pesar de estar nutridas dichas esencias de expresiones enérgicas. El Palacio Real, en su multiplicidad de sistemas y en su clara versatilidad, es obra que se siente sentir en si misma por un acusado deseo de libertad, motivada, esta libertad, en primer lugar, por la convicción en la superioridad de una idea de la que nunca 
quiso emanciparse ni olvidarse, el pasado histórico español, o también, la rebeldía ante toda norma y toda ley, subyacente en los estilos en vanguardia, que no quiso adoptar de la época en la que se construye.

No pretendemos desviarnos de lo que consideramos su componente esencial: el ser primacía del sentimiento barroco de una época, de su racionalismo o de su claro irracionalismo. Tampoco nos queremos dejar influir por los impulsos emocionales que nos han transmitido los estudiosos que se acercaron al edificio, y, rigurosamente, lo desvelaron en sus múltiples valores científicos. En esta ocasión, queremos sentirnos espectadores libres del Palacio Real, y desde una postura de marcado individualismo, de intuición, o, incluso, de propia inspiración, expresar, desde nuestra mirada, el pleno alcance que nos merece esta espectacular obra de la Edad Moderna en su grandeza, en su servidumbre, e, incluso, en lo ideal o universal de sus contenidos artísticos que, por ser tan insólitos, llegan en algunos casos a renegar de toda legislación académica.

En su nobleza y sinceridad estructural, el Palacio queda marcado, de manera clara, con el criterio sobre cómo se ha de concebir la obra de arte. Es por ello este edificio, ideal de armonía, modelo, y canon. El arquitecto dirige su imaginación, al dibujarlo, mucho más allá de las realidades cotidianas. Se eleva sobre la rutina de la construcción doméstica proclamando su distancia inconmensurable, su elevación y su distanciamiento sobre la serialidad urbana. Su misión era crear e iluminar los postulados de vida autoritarios, alejados de la fragilidad y el desorden, y sustentarlos en la belleza, la razón, la proporción y la armonía, brindándolos en una unidad paradigmática, o tan sólo, como una original forma de manifestación cultural plena del siglo XVIII.

Juan Bautista Sachetti, en nuestro criterio, es el creador del Palacio Real en términos absolutos. En su verificación no se interceptan otras estrofas ni otros ritmos. Los famosos proyectos de Filippo Juvarra de 1735, marcados por el subjetivismo artístico espectacular de este gran artífice, permiten dar razón de que Juvarra planteó una huida total de la arquitectura tradicional hispánica. Fueron diseños carentes de realidad y de comprensión. Remediaban el sentimiento de orfandad italiana o europea que tenía la Corte Española, pero a su vez, justificaban, también, su rebelión hacia la llamada nostalgia del pasado hispánico. Los proyectos de Juvarra, en su pleno alcance, fueron el producto de un momento histórico de crisis, y de una actitud personal y vital, sustentada en la idea de dar forma a lo más nuclear de una política autárquica, que busca, en lo inconmensurable, nuevos apoyos y estímulos sobre una España monárquica casi agotada. Los diseños 


\section{Lo Tradicional, lo ideal y lo universal del Palacio Real}

de Juvarra coinciden, en todos sus rasgos, con las líneas impersonalizadas de los palacios europeos de aquel tiempo, y, no es extraño, por ello, que sobre consideraciones de lugar, tiempo y acción, fuesen apartados a la muerte de su artífice, en enero de 1736 . No recrearon la arquitectura palacial tradicional española, ni siquiera pretendieron evocarla, sino más bien anularla. No fueron diferentes a los diseños destinados a los palacios contemporáneos de Francia, Austria, Alemania o Italia; fueron, tan solo, el paradigma del cambio solicitado por una Monarquía con espíritu franco-italiano ${ }^{1}$.

El proyecto del Palacio caminó sobre el vacío entre 1736 y 1738. En esta fecha, más o menos, Juan Bautista Sachetti había sido seleccionado para emprender la obra del Nuevo Palacio Real, requerido por Felipe V tras el incendio de viejo Alcázar de los Austrias. Dura prueba para un joven arquitecto, aunque ya había sido probada su capacidad profesional y talento en tierras del Piamonte, donde también había percibido enseñanzas del arquitecto Filippo Juvara, y de otros artistas al servicio de los Saboya. Venía de una escuela de gran impulso emocional, en la que se consiguió, de modo genial, la compenetración arquitectónica italo-francesa-vienesa, junto a los nuevos valores de la disgregación y antítesis del factor ornamental. Todo ello ha de ser confluyente en la obra de Sachetti, pero la evaluación favorable de este arquitecto, estuvo en el inicio, y sobre todo, en la no aversión hacia los valores del pasado palacial hispánico. Sachetti trasladó su Palacio, simbólica y funcionalmente, al viejo centro de influencia y de poder de la capital, lo cual significa el decidir sustentarlo sobre la huella del viejo Alcázar. Con ello ofrecía un signo de respeto a la antigüedad o estabilidad de la antigua Villa, a sus propias esencias, postura que pudo significar un reto en una capital en tiempo de cambios políticos e ideológicos sensibles. Parece tener presente que en aquel promontorio:

\section{«..había nacido la Villa}

con crecimiento de occidente a oriente

como si marchara a la búsqueda del sol

en carrera contraria» ${ }^{2}$

Sachetti volvió su mirada hacia aquellos hacedores de la antigua Villa y capital que habían mostrado, como lugar privilegiado, su alta colina del norte, convirtiéndola en enseña o faro político, en roca o castillo fortificado del Monarca, o como respiro en las responsabilidades políticas, al tender la mirada del Palacio hacia el campo. Amado Nervo al contemplarlo desde la calle Bailén escribe: 


\section{Virginia Tovar Martín}

"Luis ve desde su balcón lo que se ve desde el Palacio Real

Tiene este visual privilegio del cual se ufana,

porque mirar es para él la vida,

mirarlo todo, y sobre todo

la Naturaleza ${ }^{3}$

El Palacio se hacía para una sociedad diferente de la precedente, pero la colina representaba el monopolio del antiguo poder que resucitó a Madrid en la Historia, así como el espacio sagrado y defensivo de la ciudad renaciente. Un prestigioso historiador escribió no hace muchos años: Los Borbones quisieron afirmar su dinastía sobre las cenizas de la pasada y concibieron un Palacio, firme como una roca, solo, y avanzado como un bastión, de cara a la llanura y en diálogo con la sierra, de espaldas al miserable villorrio que detrás mendigaba favores ${ }^{4}$.

Sachetti, aunque estaba profundamente ligado a los cambios culturales, supo asociar a las virtudes que reconoció en los antepasados hispánicos, una tipología de lujo, unas formas geométricamente regulares sobre un terreno desigual, y unas plataformas diseñadas sobre diferentes niveles y ejes. Su ideología se sustentaba entre la introspección y aislamiento urbano, y la extraversión paisajística que pasa a ser para él un aspecto principal de motivación. El Palacio se inserta, orgánicamente, en el paisaje que le rodea y del que es parte integrante. Pero ésta no fue una forma nueva ni primera de conceptualizar la arquitectura de la cornisa occidental de la capital; fue, simplemente, el volver a calificarla de la misma forma que en periodos anteriores, porque no ignoraba que en aquel lugar, el Palacio se convertía en piedra de toque de Madrid, en el fiel contraste imposible, en la medida tope que tiene el almacenero de nuestra monumentalidad ${ }^{5}$. Era el lugar elegido el gran barranco de Madrid, es el primer camino que siguen los procreadores de la Corte. Por allí se engalanan, se agarran de las raíces:

que son asas del monte, saben que escalan

la Corte del futuro»

No plantea competencia a la tradición existente, sino que por el contrario, persigue un coloquio con ella, entrelazándola con una renovada expresión a la que se agregan contribuciones teóricas de valor universal, basadas en las poéticas de una amplia tratadística moderna. Sachetti, guiado por esta mirada retrospectiva, tuvo en cuenta las 


\title{
Lo Tradicional, lo ideal y lo universal del Palacio Real
}

condiciones específicas del terreno en el que estuvo asentado durante varios siglos el Alcázar, incorporando, al proyecto, el mismo anexo amplio de huertas y jardines. Tampoco prescinde en su diseño de entender el Palacio Nuevo como una amalgama de elementos sacros y profanos. Como resultado de sus complejos tanteos y deliberaciones, decide la inserción de la Capilla Real en el eje céntrico del vasto conjunto, tal vez, postulando, también, con carácter analógico en su planteamiento, una defensa en el recuerdo de la lección recibida de la Capilla Real del desaparecido Alcázar, modernizada por Luis de Vega y Alonso de Covarrubias. Pero no se trata de un problema de mimesis que pudiera desestabilizar la nueva obra, se trata de una clara tendencia de superación del experimentalismo occidental en el que nace, pero sin renunciar al soporte historiográfico que, deliberadamente, compromete en el concepto morfológico del Nuevo Palacio.

A nuestro juicio, Sachetti se satisface construyendo sobre el emplazamiento del castillo-palacio anterior: acepta las irregularidades de la construcción antigua; respeta el trazado sobre un sistema cuadrangular; agrupa la estructura en torno a un patio; cada fachada tiene una concepción de acuerdo con la escarpadura del terreno; incorpora cuerpos en torreta que recuerdan las torres angulares antiguas; y quiebra el eje axial con la inserción de la Capilla en un espacio central verificado con pequeñas unidades alrededor que, hacen aprehensible en el exterior lo sagrado, al convertir la cúpula en el componente de la vertical dominante. Con todo ello, no deja de tener en cuenta la percepción visual del edificio palacial tradicional hispánico. También elige el granito como materia básica, porque tampoco olvida que fue el material por excelencia de la arquitectura española del pasado, animado, seguramente, por la diversificación de su grano y su color. No debe extrañar que alguien en aquel tiempo, en su poética, empleara para definir el edificio nuevo la palabra «Alcázar» 6.

\author{
«Aquel de berroqueña y blanca piedra \\ que entre todos los otros se señala \\ es el Alcázar Regio donde habita \\ hoy el piadoso Carlos, con las ramas \\ del claro tronco de su regia estirpe \\ asiento venturoso de la gloria \\ del valor, el talento y las virtudes»
}

Desde su impecable organización formal se asiste a un fatigoso trabajo de penetración en las estructuras lingüísticas hispánicas, po- 
niendo en juego un código institucional, entonces, por razones políticas, casi obsoleto. Turín había perfilado la personalidad de Sachetti y no cabe duda que tenía madurez técnica e intelectual cuando llega a España. No renuncia a la imponente arquitectura que ha de representar el poder de Felipe V, pero el Palacio es obra de un concepto estético propio, en cuya elaborada trascendencia no dejó aislado ni invalidado el pasado artístico español. Sachetti entendió el diseño del Palacio Real de Felipe V, como matriz determinante de una serie de valores.

En el proceso constructivo del edificio, Juan Bautista Sachetti, con esfuerzo y denuedo, no aguarda pasivamente su acometida. Trabaja con tesón en base a mecanismos de prevención, de estrategia y corrección de errores. Es el auténtico «trabajador del proyecto», y no sólo «el pensador de la Idea». Es hombre silencioso que pone a prueba diariamente su capacidad y su razón, limitándose a esperar, pasivamente, si sus ideas cuadran, respetan o alcanzan la realidad española. Imaginamos un cierto sentimiento de desasosiego, pero su proyecto sobrevive de manera irreversible. Sachetti ha pensado en el Palacio de Felipe V sin desarraigarlo de la Historia Española, por este motivo su proyecto nace sobre la materia calcinada del viejo Alcázar, como la respuesta-fin de una simbólica necesidad histórica, a la que condesciende sin vacilación, Felipe V. Estudia, sin duda, lo positivo de este contagio. El Palacio ha de reducirse en el tamaño adaptándose a la vieja colina, respetando su simbolismo, pero también, arquitectónicamente, ha de estar conectado con ámbitos de competencia europea, conduciéndole, no sólo hacia una superación de las tradiciones hispánicas, sino también hacia el alcance de sistemas figurativos actualizantes.

F. de la Plaza, en su espléndida monografía del Palacio Real, indica el sustrato de vitalismo que domina esta obra ${ }^{7}$. La aguda aportación historiográfica sobre este edificio en pro de su idealización, le han convertido en «tipo»y en «modelo»" ${ }^{8}$, pero sobre todo, el sólido experimentalismo de su autor, Juan Bautista Sachetti, confirma que hubo un deseo expreso de crear un organismo modulado y comprometido con la mejor arquitectura de su tiempo. Sachetti, a nuestro juicio, se siente obligado a realizar una síntesis al modo de un acto reflejo basado en la órbita artística de Hardouin Mansard, Filippo Juvara, G. L. Bernini, F. Von Erlah, De Cotte y otros arquitectos de vanguardia. Plantea un sistema de competencia, o mejor, un desafío a las variadas interpretaciones que confluyen en el complejo campo de las experiencias palaciales europeas. El Palacio no fue un ensayo en el que se proyecta la unicidad franco-italiana, ni estuvo alineado en la autonomía de otras experiencias figurativas nórdicas, como tampoco fue una prueba 


\section{Lo Tradicional, lo ideal y lo universal del Palacio Real}

de la desconfianza del Rey Felipe $\mathrm{V}$ hacia las técnicas y simbología de la arquitectura española. Todos los elementos fueron tomados en consideración, pero el Palacio nace sin voluntad mimética ni analógica, con una clara tendencia de superación del amplio experimentalismo occidental en el que surge. El Nuevo Palacio de Sachetti no fue un artístico «bricolage», ni mucho menos una polifonía morfológica bien compuesta, que pudiera correr el riesgo de ser transferida a un concepto de ambigüedad.

En la propia plasticidad de su materia, se subraya su consciente e inteligente polivalencia, en la que se expresa, cumplidamente, la búsqueda de la continuidad entre el pasado y el presente. En su casuística tipológica, se entrelaza una renovada tradición humanística que incluye contribuciones teóricas de valor universal basadas en poéticas de la Antigüedad, en Alberti, SanGallo, Palladio etc. Se insertan en él voces elegidas como expreso reconocimiento a la concepción dogmática renacentista, y representa una defensa del enraizamiento en los postulados de los teóricos puros. Nos acerca a la quimera serliana, a la casuística de la «licencia» como sistema de emoción estética, legitimando, en sus elementos, el subjetivismo o la simple ambigüedad como maneras válidas y emotivas.

El Palacio integra rasgos destacados de funcionalidad y racionalidad, porque en él se asume la inquietante cultura del barroco. Lleva inserta la poética guariniana y juvariana y aboga por la cultura italiana del «seiscientos», replanteando tradiciones barrocas clasicistas berninianas. Indaga en el propio policentrismo perspectivo y se concentra, también, en la fase experimental avanzada de lo francés y lo vienés, situando la investigación en las fuentes de Le Vau, Mansard, Perrault, Juvara, Vittozzi, De Cotte, Hildebrand y Von Erlach.

Las referencias decorativas son extraídas de una atenta observancia de la obra piamontesa sobre todo, pero Sachetti, voluntariamente experimental, reconduce las leyes de la más pura estereometría a una dialéctica combinatoria con la que no refuta, sino que persigue el encuentro armónico de términos histéricamente enfrentados. El Palacio es el fruto inteligente de antitéticos componentes formales. De ninguna manera es monocorde. En él se filtran, con sabia habilidad, postulados ideológicos del clasicismo bajo nuevos significados componentes buscados en las tensas e inquietas experimentaciones del manierismo, y valores del barroco más exultante. Con todo ello, compromete su atención a los ritmos sincopados y geométricos del palacianismo hispánico. Sachetti diseña sobre una clara idea basada en múltiples e implícitas sugerencias polivalentes. 
El Palacio, casi desnudo estructuralmente, representa una vuelta a un sintetismo geométrico impecable, sin embargo se insertan en él conceptos diferentes, e, incluso, en algún caso opuestos. Pero sus variados matices fueron sabiamente integrados, expresándose la idea de que, el uso de la libertad en esa compleja polifonía figurativa, se convirtiera en «virtud» arquitectónica, en meritoria síntesis. F. Chueca lo define como:

"Navío de gran porte, es el edificio de mayor calado del mundo

varado a orillas del más menguado río»

No es casual que en su propia proyección urbanística abogara por el distanciamiento perspectivo, configurando la idea de «espacio teatral», y poniendo en juego el factor emocional y la recuperación de su imagen inserta en el atributo de la «visualidad». En esta inserción urbana, Sachetti afronta el espacio eclesiástico en una clave de método hispánico. Como ya hemos indicado, otorga a la Capilla palacial el valor de interlocutor urbano, ofreciendo la cúpula como ámbito central de la existencia. Sachetti construye el edificio subordinando su imagen a la lejanía, comprometiendo el edificio en el plano de una sucesión de espacios y de secuencias atmosféricas, forzando los códigos de color y de movilidad congénitos a la inmensidad que plantea, en las que se incluyen bosques, montañas y celajes de la serranía. Así Pio Baroja pudo escribir:

\section{«El Palacio al anochecer \\ mas que un conjunto de piedras \\ es una masa de rosa pálido \\ en un cielo de ópalo» 9}

El paisaje es argumento complementario. Recortado el edificio sobre la línea del horizonte, su volumen queda alejado de la ciudad preexistente desintegrado del continuismo ciudadano. Sachetti indaga en los valores de una «arquitectura distanciada» buscando el inequívoco testimonio de una estructura poderosa entregada al exhibicionismo.

Existe en el edificio una clara corriente canónica. En su equilibrio estructural se salvaguarda una normativa relacionada con la tradición del cinquecento. Al modo de Lescot, quiebra las líneas horizontales y resalta las verticales, $\mathrm{y}$, siguiendo a Du Cerceau, construye alrededor de un patio cuadrado, recreándose en la profusión de efectos super- 
ficiales. Avanza la fachada audazmente hasta la escarpadura aguda occidental buscando su atractivo, poniendo en marcha una inventiva y una destreza estructural propias del medievo. Los bloques se definen en términos cúbicos y la cornisa horizontal y el orden continuo, elevado sobre un amplio basamento, proceden de Miguel Angel. También el diseño en bloque, la cubierta plana, la balaustrada con estatuas y las paredes con orden colosal formado por columnas y pilastras adosadas, evocan los diseños clásicos de Caprarola y Montecitorio. Sachetti demuestra su dominio de la arquitectura clásica, y, al mismo tiempo, un sentido de la gran escala. Se deja influenciar por la doctrina clásica y racionalista de Jules Hardouin Mansard, invocando las leyes de la razón más que la fantasía, porque busca el orden y porque sabe que, sólo por medio de éste, puede hacerse la arquitectura aprehensible a la mente humana. Su imaginación se ancla fuertemente en la serena oferta renacentista, tal vez, queriendo atestiguar los términos dialécticos del gran clasicismo, tanto francés como italiano. Como otros edificios que nacen con el signo de la magnificencia, no estuvo libre de adversidades, por ello nacieron un número muy destacado de dibujos, muchos de los cuáles permanecieron en el papel, pero quedaron como muestra de un sólido proceso creador.

Al modo italiano el piso bajo funciona como base para los pisos superiores. También pueden ser precedentes italianos el uso del orden colosal en fachada y la concentración de medias columnas en el área central para realzar la entrada, no sólo con referencia a Bernini, sino también a fórmulas miguelangelescas y palladianas. El rico orden de composición de pilastras, la poderosa cornisa coronada por balaustrada con estatuas que implican esculturas, y la fuerte acentuación de la entrada o el balcón, se remontan al Palacio Farnesio de Roma. Pero Sachetti supo romper el modelo romano renacentista, que no tuvo articulación vertical, introduciendo filas de ventanas tendidas horizontalmente por molduras lineales continuas, y creando una bella gradación desde los marcos sencillos de las ventanas, a los elaborados marcos-tabernáculos del piso principal. Conservó la cornisa unificadora, el horizonte no interrumpido, y los cuatro pabellones coronados por cuerpos torreados para enmarcar cada uno de los cuatro frentes. La pared exterior forma una envoltura continua y cerrada, pero quedó diferenciada verticalmente, expresando, también, el carácter de los espacios interiores. La planta tiende a una simetría axial, pues Sachetti decide introducir un eje longitudinal en el Patio, que atraviesa el edificio uniéndolo a la Capilla Real, 
para acentuar el centro de la fachada norte del patio con una arquería triple y un segmento de frontón, que refuerza el espacio sacral.

El Palacio se entiende como una síntesis de las exigencias de la época, por ello es espacioso, representativo y dominante. Pero a pesar del deseo general de sistematización, Sachetti emplea los órdenes clásicos como elementos constitutivos de la osamenta del edificio, y se aparta de la pared-membrana perforada con aberturas, tan extendida en la primera mitad del siglo XVIII. Hubo en aquella época cierto pluralismo de medios expresivos y de unificación inteligente de tendencias italianas y francesas, como fue el ejemplo de Austria, formando una arquitectura palacial, excepcionalmente flexible, que no tardaron en adoptar Ficher Von Erlach, Boffrand y Juvara, entre otros. El barroco tardío conservó la creencia en la validez de la amplia síntesis, mientras que el rococó tomaba como punto de partida la diferenciación e individualidad, y la supresión de los órdenes clásicos.

El estilo claro y vigoroso del Palacio representa la manifestación ideal del absolutismo estatal. En estos aspectos fue Francia quien supo ofrecer el hechizo de una arquitectura de Estado. Sachetti conoce, sin duda, que Francia ha sido la espina dorsal de un sistema palacial diferenciado. El arquitecto, tras el estudio vigorizante de los elementos clásicos, busca espacialidad y bellas perspectivas, confiando la cintura del nuevo edificio a una mirada de movimiento giratorio que se apoya en Le Nôtre, y De Cotte, también en Francia. Los jardines, en ejes verticales y horizontales, equilibran, en el exterior, la composición, y aglutinan la directriz de visión hacia el eje central de cada fachada. Forman, por el norte y por el oeste, un módulo de considerable anchura, y prestan una delicada animación rítmica. Los jardines no se realizaron pero quedaron como una clara concesión al arte que Felipe V había vivido en su infancia versallesca.

Sachetti, con su estilo propio, había creado un Palacio Nuevo monumental en forma de bloque, con cubierta plana y balaustrada al modo de Versalles. La cornisa horizontal y la articulación de las paredes con orden colosal, como definición clara y sencilla de los volúmenes, recuerdan el Palacio del Louvre. Los bloques definidos en términos cúbicos, quedando interrumpidas las superficies por frontispicios salientes, también son de recuerdo versallesco, como lo son la simetría y el orden que aplicó a los patrones geométricos de su entorno. Sachetti dejó que la materia, granito y piedra blanca, ofrecieran todo su valor sensible; pero intuitivo e inteligente, puso en marcha lo mejor de la arquitectura de su tiempo. Supo aprovechar la sabiduría en el desarrollo del tema palacial del que, tal vez, fue su principal maestro, F. Juvara. 


\title{
Lo Tradicional, lo ideal y lo universal del Palacio Real
}

Pero buscó, también, la exhuberancia y el noble y florido clasicismo de Bernini, y se adueñó del libre estructuralismo de lo francés y lo vienés. Por ello, el Palacio de Sachetti no es el fruto de un solo pensamiento, sino la mezcla de diversos ingredientes que no se ocultan en el concienzudo estudio, subyacente en la definición de sus espacios. Tomó apuntes de Miguel Angel, no olvidó el porte de Le Vau, Bernini, y H. Mansard, se sintió estimulado por el admirado Guarino y por Vittozzi, y no dudó en añadir una invocación hispánica.

En la textura llamativa de las cuatro fachadas, en su piel mural todo se desliza suavemente, uniformemente, sin apenas particularizar los ricos detalles de su materia ósea. Pero la virtuosa técnica de Sachetti proporciona una imagen de gran fuerza tridimensional, porque fue lúcido y agudo en la dirección de las partes escultóricas del conjunto. Quiso brindar al Rey Felipe V una residencia igual o superior a la de los Monarcas y príncipes contemporáneos. Sachetti sabía que su destino era convertirse en el principal arquitecto de la Residencia Real, y sólo le obsesionó el dedicarse integralmente a ella. Logró superar el diseño de una figura tradicional, ofreciendo una arquitectura orgánica viva. Quiso que el Palacio fuese el hito que señala el nacimiento de Madrid, la piedra simbólica de su fundación y el signo del poder monárquico resurgente. El Palacio debería ser un «monumento conmemorativo» que simbolizase, por una parte, la antigüedad árabe-cristiana de la capital, y, especialmente, la cultura artística universal de los Borbones.

Alguien afirmó que el Palacio era un sólido tan compacto, que podía rodar colina abajo sin dañarse. Pasado el tiempo aún se evocaba el edificio de esta manera:

\author{
Mudos contemplaron su mole oscura y misteriosa \\ tanto balcón cerrado, tanta pilastra robusta, \\ las ingentes paredes, \\ aquel aspecto de tallador de montaña, \\ con la triple expresión de Majestad \\ grandeza y pesadumbre.... \\ materiales simbólicos del Poder ${ }^{10}$
}

\section{Notas}

1 Filippo Juvarra. Catàlogo-Exposiciòn. (1994). Madrid. GARMS, J. (1994): El proyecto de Juvarra para el Palacio Real de Madrid. Catàlogo-Exposiciòn, Filippo Juvarra, ob.ct. Número Extraordinario sobre Filippo Juvarra (1994). Reales Sitios 119. 
2 Chueca Goitia, F. (1991): El semblante de Madrid. Madrid, 67.

3 Nervo, A. (1951): El Paisaje. Obras Completas. Madrid, 1071.

4 Chueca Goitia, ob. ct. 70.

5 ChUECA Goitia, ob. ct. 71.

6 Salas, F. G. de. (1797): Poesías. Madrid T. I, 200.

7 PlazA, F. De la. (1975): Investigaciones sobre el Palacio Nuevo de Madrid. Valladolid.

8 Rodriguez, D. (1996): El Palacio Real de Madrid. Palacios Reales de España. Historia y arquitectura de la magnificencia. Madrid, 153. BotTINEAU, Y. (1986): El arte cortesano en la época de Felipe V (1700-1746). Madrid. SANCHO, J. L. (1989): «El Palacio Real de Madrid. Alternativas y críticas a un proyecto". Reales Sitios $\mathrm{n}^{\circ}$ extraord.

9 BAROJA, P. (1946): El amor, el dandinismo y la intriga. Obras Completas. Madrid. Tomo IV, 87.

10 Pérez Galdós, B. (1968): El Doctor Centeno. Madrid, 1336. 
